\title{
Los derechos de los inversores extranjeros sobre la tierra según los tratados de protección de inversiones: una visión desde Latinoamérica
}

Fecha de recepción: 9 de febrero de 2015

Fecha de aceptación: 14 de septiembre de 2015

Doi: dx.doi.org/10.12804/acdi9.1.2016.08

\section{Nicolás M. Perrone*}

Resumen: En los últimos diez años, la inversión extranjera en agricultura se ha incrementado notablemente en Latinoamérica. Inversores extranjeros tanto privados como estatales están interesados en la producción agrícola, ya sea por el beneficio esperado o para asegurarse el abastecimiento de alimentos. Este aumento de la inversión puede ser positivo para los países de la región. No obstante, para realizar esta determinación, es necesario comprender, entre otros, los efectos legales de estos flujos de inversión. Este trabajo sostiene que los derechos de propiedad que adquieren los inversores extranjeros sobre la tierra y los emprendimientos agrícolas pueden ser diferentes de los derechos de los inversores nacionales. Esto se debe a

* PhD, London School of Economics and Political Science. Docente investigador, Universidad Externado de Colombia. Agradezco los comentarios a una versión borrador de este trabajo recibidos en la conferencia de las cátedras omc de Argentina, Chile y México, titulada "Comercio agrícola y América Latina: cuestiones, controversias y perspectivas", realizada los días 19 y 20 de septiembre de 2013, en Flacso Argentina, Buenos Aires.

Para citar este artículo: Perrone, Nicolás M., "Los derechos de los inversores extranjeros sobre la tierra según los tratados de protección de inversiones: una visión desde Latinoamérica", Anuario Colombiano de Derecho Internacional (ACDI), 2016, 9, pp. 273-308. Doi: dx.doi.org/10.12804/acdi9.1.2016.08

Nota: Una versión borrador y preliminar de este trabajo fue presentada en la conferencia de las cátedras OMC de Argentina, Chile y México, titulada "Comercio agrícola y América Latina: cuestiones, controversias y perspectivas”, realizada los días 19 y 20 de septiembre de 2013, en Flacso Argentina, Buenos Aires. 
los tratados para la protección de inversión extranjera. El fortalecimiento de los derechos de los inversores extranjeros afecta la relación de estos inversores con los Estados receptores. Este artículo analiza los efectos de los derechos de los inversores extranjeros en relación con cinco categorías de iniciativas estatales. Concretamente, 1) el derecho a exportar la producción o al precio de exportación frente a medidas comerciales y tributarias; 2) el derecho a continuar el proyecto frente a cambios dentro del paradigma regulatorio; 3) el derecho a continuar el proyecto frente a cambios de política o nuevas preferencias sociales; 4) el derecho a recibir una compensación mayor frente a reformas agrarias o programas de reparación histórica; 5) el derecho a mantener su plan de negocios frente a una crisis alimentaria.

Palabras clave: derecho internacional económico, régimen internacional de inversiones, arbitraje de inversiones, inversiones extranjeras, agricultura.

\section{The Rights of Foreign Investors Over Land According to Investment Protection Treaties: a View from Latin America}

Abstract: In the last ten years foreign investment in agriculture has increased notably in Latin America. Foreign investors, as much private as state, are interested in agricultural production, either for an expected benefit, or to assure the food supply. This increase in investment can be positive for the countries of the region. Nevertheless, in order to carry out this determination it is necessary to understand, among other things, the legal effects of these investment flows. This work maintains that the property rights acquired by foreign investors over the land and their agricultural undertakings may be different from the rights of national investors. This is because of foreign investment protection treaties. The strengthening of the rights of foreign investors affects the relationship between these investors and the receiving state. This article analyzes the effects of the rights of foreign investors in relation to five categories of state initiatives. Specifically, they are 1) the right to export production or the cost of exportation in the face of commercial and taxation measures; the right to continue a project in the face of changes within the regulatory paradigm; 3) the right to continue a project in the face of political change or new social preferences; 4) the right to receive better compensation in the face of agricultural reforms or programmes of historical reparation; 5) the right to maintain the business plan in the face of a food crisis. 
Keywords: International economic law, international investment regime, investment arbitration, foreign investment, agriculture.

Os direitos dos inversores estrangeiros sobre a terra segundo os tratados de proteção de investimentos: uma visão desde a América Latina

Resumo: Nos últimos dez anos, o investimento estrangeiro em agricultura tem incrementado notavelmente na América Latina. Inversores estrangeiros tanto privados quanto estatais estão interessados na produção agrícola, seja pelo benefício esperado seja para se assegurar o abastecimento de alimentos. Este aumento do investimento pode ser positivo para os países da região. No entanto, para realizar esta determinação é necessário compreender, entre outros, os efeitos legais destes fluxos de inversão. Este trabalho sustenta que os direitos de propriedade que adquirem os inversores estrangeiros sobre a terra e os empreendimentos agrícolas podem ser diferentes dos direitos dos inversores nacionais. Isto deve-se aos Tratados para a Proteção de Investimento Estrangeiro. O fortalecimento dos direitos dos inversores estrangeiros afeta a relação destes inversores com os Estados receptores. Este trabalho analisa os efeitos dos direitos dos inversores estrangeiros em relação com cinco categorias de iniciativas estatais. Concretamente, 1) o direito a exportar a produção ou ao preço de exportação frente a medidas comerciais e tributárias; 2) o direito a continuar o projeto frente a mudanças dentro do paradigma regulatório; 3) o direito a continuar o projeto frente a mudanças de política ou novas preferências sociais; 4) o direito a receber uma compensação maior frente a reformas agrárias ou programas de reparação histórica; 5) o direito a manter seu plano de negócios frente a uma crise alimentaria.

Palavras-chave: direito internacional económico, regime internacional de investimentos, arbitragem de investimentos, inversões estrangeiras, agricultura.

\section{Introducción}

En muchos países latinoamericanos, el sector agrícola juega un papel fundamental tanto en la economía como en la vida de sus comunidades. El recurso clave para las actividades agrícolas es la tierra, y una pieza fundamental para la realización de estas actividades son los derechos sobre la tierra y la 
producción. Gran parte de las relaciones económicas y sociales creadas por la agricultura se deben o tienen su origen en los derechos que el orden jurídico reconoce sobre la tierra. Si bien históricamente la agricultura ha sido fundamental para la región, durante los años posteriores a la Segunda Guerra Mundial esta actividad pasó a un segundo plano en virtud de los procesos de industrialización por sustitución de importaciones. A partir de la década de los noventa, el auge del neoliberalismo devolvió a la agricultura un rol protagónico en varios países latinoamericanos, especialmente en el Mercosur. ${ }^{1}$ Y ya para mediados de los años dos mil, la agricultura había recuperado un papel preponderante para las economías de la región en virtud del aumento de los precios internacionales. Los productos agrícolas volvieron a dominar las exportaciones de muchos de los países de la región, incluido Brasil. ${ }^{2}$ Junto con el aumento de la demanda y consiguiente alza de los precios, los flujos de capital extranjero comenzaron a prestar más atención a la agricultura como potencial destino de inversiones extranjeras. En este sentido, un estudio de la FAO ha destacado el interés de actores extranjeros en adquirir tierras o participar indirectamente en actividades agrícolas a través de fondos de inversión. ${ }^{3}$

La inversión extranjera en agricultura, y específicamente la adquisición de derechos de propiedad sobre la tierra por extranjeros, tiene una importancia particular en virtud del régimen internacional de inversiones. A partir de la década de los noventa, muchos países latinoamericanos comenzaron a firmar tratados para la protección de inversión extranjera (TPIE). Estos tratados forman parte de la receta neoliberal para el desarrollo económico. En lo que respecta a inversiones extranjeras, la premisa que guió los consejos del Banco Mundial, la Organización para la Cooperación y el Desarrollo Económico, y otros organismos internacionales es que los países deben atraer la mayor cantidad de inversión extranjera posible. Para ello, deben dar libertad al inversor para que establezca su proyecto,

1 Bonnal, Philippe; Bosc, Pierre Marie; Díaz, Mario \& Losch, Bruno, "Multifuncionalidad de la agricultura y 'nueva ruralidad'. ¿Reestructuración de las políticas públicas a la hora de la globalización?", ponencia presentada en el Seminario Internacional El Mundo Rural: Transformaciones y Perspectivas a la Luz de la Nueva Ruralidad, Pontificia Universidad Javeriana, Clacso, Redcapa, Bogotá, 15-17 de octubre de 2003, pp. 5-8; Segrelles, José Antonio, "Una reflexión sobre la reciente reorganización de los usos agropecuarios en América Latina", Anales de Geografía de la Universidad Complutense, 2007, 27, (1), p. 125.

2 Gayá, Romina \& Michalczewsky, Kathia, "El salto exportador del Mercosur en 20032008. Más allá del boom de las materias primas”, IDB-Intal, 2011, nota técnica 292.

3 FAO, Dinámica del mercado de la tierra en América Latina y el Caribe: concentración y extranjerización, Naciones Unidas, Roma, 2012. 
y asegurar las condiciones de la inversión frente a cambios políticos y arbitrarios. ${ }^{4} \mathrm{Si}$ bien hoy existe un importante debate sobre los TPIE y el arbitraje de inversiones, especialmente en lo que concierne al derecho a regular, el consenso económico dominante continúa remarcando el rol fundamental de la inversión extranjera para el desarrollo. ${ }^{5}$

Los TPIE constituyen en este esquema una especie de Gran Acuerdo o 'Grand Bargain', por el cual los países aceptan estándares internacionales para la protección de la inversión extranjera luego de su establecimiento, a cambio de aumentar sus posibilidades de recibir inversión extranjera. ${ }^{6}$ En la práctica, no obstante, los TPIE no solo protegen la inversión extranjera, sino que también tienen efectos —a través de la interpretación que hacen los árbitros de inversiones - sobre el contenido de los derechos de los inversores extranjeros. Como destaco en otro trabajo, la mayor parte de la literatura en el derecho de inversiones extranjeras se ha ocupado del procedimiento para ejecutar la protección: el arbitraje de inversiones; de quiénes deciden estos casos: los árbitros de inversiones; y del contenido de los estándares de protección: expropiación indirecta, trato justo y equitativo, prestando menos atención a los derechos de los inversores extranjeros. ${ }^{7}$ No obstante, para los inversores la protección brindada por los TPIE solo tiene sentido en la medida que incrementa su control sobre los recursos ubicados en los países receptores. Nadie invierte para iniciar un arbitraje de inversiones, al menos, de buena fe.

Como menciona Joseph Stiglitz: "BITs give property rights to investors, a result that may have distributional consequences". 8 Así, cuando están cubiertos por un TPIE, los inversores extranjeros adquieren derechos sobre la tierra

4 Kaushal, Asha, "Revisiting history: how the past matters for the present backlash against the foreign investment regime", Harvard International Law Journal, 2009, 50, (2), p. 491.

5 Ver Unctad, World investment report 2012: towards a new generation of investment policies, Naciones Unidas, Nueva York y Ginebra, 2012.

6 Salacuse, Jeswald \& Sullivan, Nicholas, "Do BIT really work?: an evaluation of bilateral investment treaties and their Grand Bargain", Harvard International Law Journal, 2005, 46, (1), pp. 76-7; Salacuse, Jeswald, "The emerging global regime for investment", Harvard International Law Journal, 2010, 51, (2), p. 427.

7 Perrone, Nicolás, The international investment regime and foreign investors' rights: another view of a popular story, PhD thesis, London School of Economics and Political Science, 2013, pp. 12-27; Perrone, Nicolás, "The international investment regime and foreign investors' rights: another view of a popular story", Manchester Journal of International Economic Law, 2014, 11, (3), p. 397.

8 Stiglitz, Joseph, "Regulating multinational corporations: towards principles of cross- 
agrícola que pueden ser diferentes de los que adquiere un inversor nacional que no puede acceder a un arbitraje de inversiones. Esto es muy importante para la relación entre el Estado y los inversores extranjeros en el sector agrícola, ya que las acciones de los Estados que afectan a los individuos deben ser tomadas siguiendo cierto procedimiento, y deben respetar los derechos de los individuos. El carácter abusivo o arbitrario de la conducta estatal depende del contenido de los derechos privados. ${ }^{9}$

El presente trabajo tiene por objetivo analizar las diferencias entre los derechos de los inversores extranjeros y los nacionales en el contexto agrícola, y los efectos concretos que estas diferencias podrían tener frente a ciertas medidas de los Estados. Este análisis se suma a otros estudios realizados en Latinoamérica que discuten los efectos de los TPIE en otras áreas socialmente sensibles, como son, por ejemplo, los servicios públicos y el derecho al agua. ${ }^{10} \mathrm{La}$ primera parte presenta el marco teórico y metodológico para este análisis. Este marco se nutre de conceptos de teoría general de la propiedad y del derecho constitucional de la propiedad. La segunda parte expone la fórmula que utilizan los tribunales arbitrales internacionales para sustanciar los derechos de los inversores extranjeros: las expectativas legítimas. Esta fórmula no es necesariamente la utilizada por las jurisdicciones nacionales. Finalmente, la última parte explora cinco escenarios en los que los derechos de los inversores extranjeros sobre la tierra, según los TPIE, tendrían efectos concretos frente a iniciativas públicas. Se trata de 1) el derecho a exportar la producción o al precio de exportación frente a medidas comerciales y tributarias; 2) el derecho a continuar el proyecto frente a cambios dentro del paradigma regulatorio; 3) el derecho a continuar el proyecto frente a cambios de política o nuevas preferencias sociales; 4) el derecho a recibir una compensación mayor frente a reformas agrarias o programas de reparación histórica; 5) el derecho a mantener su plan de negocios frente a una crisis alimentaria.

border legal frameworks in a globalized world: balancing rights with responsibilities", American University International Law Review, 2008, 23, p. 517.

9 Jennings, R. Y., "State contracts in international law", British Yearbook of International Law, 1961, 37, p. 165 y nota 3.

10 Ver, por ejemplo, Bohoslavsky, Juan Pablo, "Tratados de protección de las inversiones e implicaciones para la formulación de políticas públicas (especial referencia a los servicios de agua potable y saneamiento)", Cepal, Colección Documentos de Proyectos, 2010; Lentini, Emilio \& Fierro, Gonzalo, "Políticas tarifarias y regulatorias en el marco de los Objetivos de Desarrollo del Milenio y el derecho humano al agua y al saneamiento", Cepal - Serie Recursos Naturales e Infraestructura No 164, 2014. 
Este artículo concluye que los Estados que han suscripto TPIE deben ser especialmente cautelosos tanto al recibir inversión extranjera en agricultura como al tomar medidas respecto de esos emprendimientos extranjeros. Los derechos de propiedad privada otorgan autoridad a los individuos y limitan la actividad estatal. Dada la complejidad que encierran los arbitrajes sobre inversiones, no se hace un pronóstico sobre posibles disputas. El objetivo, en cambio, es ilustrar los límites que imponen los derechos de los inversores extranjeros en el marco de los TPIE y los arbitrajes de inversiones. A través de este análisis se demuestra, con especial detalle, los efectos discriminatorios que tienen estos tratados a favor de las inversiones y los inversores extranjeros.

\section{Los TPIE y los derechos de propiedad de los inversores extranjeros sobre la tierra y los emprendimientos agrícolas}

El objetivo de esta primera parte es presentar las premisas que sustentan el argumento de que el contenido de los derechos de los inversores extranjeros es diferente de los inversores nacionales. La primera sección muestra que la idea de dominio se centra en que el individuo puede elegir el uso de sus recursos, y la comunidad — tanto otros individuos como el Estado- debe respetar esta decisión. ${ }^{11}$ Para los inversores, la protección de sus derechos de propiedad debe tener en cuenta esa elección económica concreta, y no ser una simple protección en abstracto. La segunda sección analiza los derechos de propiedad dentro del orden jurídico. El orden jurídico nunca establece el dominio sobre los recursos en forma clara y completa. Cuando existe un conflicto entre un inversor extranjero y un Estado en el marco de un TPIE, los árbitros de inversiones deben clarificar el contenido de los derechos de los inversores extranjeros para resolver la controversia. La tercera sección estudia la labor interpretativa de los árbitros internacionales en relación con los derechos de los inversores extranjeros. Finaliza señalando que, para determinar el contenido de los derechos, los árbitros recurren a la fórmula de las expectativas legítimas, una fórmula que no necesariamente coincide con la utilizada por la legislación y los jueces nacionales.

11 Waldron, Jeremy, The right to private property, Clarendon Press, Oxford, 1988, p. 52. 


\subsection{Derechos de propiedad y arbitraje de inversiones}

Los inversores extranjeros establecen sus proyectos a fin de realizar una actividad económica que tiene por objetivo crear valor. Su principal propósito es poder apropiarse de parte de ese valor: su ganancia. Antes de decidirse a invertir, los inversores extranjeros analizan una serie de factores, entre ellos, las ventajas que ofrece el país receptor. En el caso de inversiones en el sector agrícola, un elemento central es el recurso tierra. Los inversores extranjeros obviamente prefieren tierras que ofrezcan mayor productividad. Aparte de las condiciones propias del recurso tierra, existe otra serie de factores que influyen en la productividad agrícola: la existencia de mano de obra, de recursos humanos calificados, de infraestructura, la legislación en la materia y el comportamiento de los organismos de regulación y control. Luego de considerar todas estas variables, el inversor extranjero decide establecer su proyecto. ${ }^{12}$

Las expectativas respecto del valor a crear y las ganancias se sustentan en una serie de factores dentro de los cuales el recurso tierra juega un papel preponderante, pero también ciertamente abstracto. Las expectativas puestas sobre la productividad y los beneficios que generará la inversión dependen del uso que el inversor extranjero haya planificado para el recurso, como también de las condiciones de comercialización del producto. Entre varios factores, esta planificación depende de la legislación y regulación en la materia. El Estado, por ejemplo, puede alterar a través de mecanismos tributarios y comerciales el precio que obtiene el inversor por la producción. Los inversores extranjeros buscan hacerse del precio internacional del producto agrícola, sobre todo si se trata de commodities. Si por cualquier motivo el inversor extranjero no puede acceder al mercado internacional, es posible que no logre alcanzar el total del beneficio esperado. ${ }^{13}$ La expectativa del inversor extranjero, en suma, no es realizar cualquier actividad que genere valor para apropiarse de algún beneficio, sino llevar a cabo la actividad planificada para alcanzar el beneficio esperado: por ejemplo, producir soja para exportación.

\footnotetext{
12 Dunning, John \& Lundan, Sarianna, Multinational enterprises and the global economy, $2^{\mathrm{a}} \mathrm{ed}$,, Edward Elgar, Cheltenham, UK, Northampton, MA, 2008, pp. 95-109.

13 Perrone, Nicolás, "La inversión extranjera en agricultura y los altos precios de los productos primarios: un aporte para comprender el actual desafío del Mercosur", Revista Comercio e Integración, 2012, 35, pp. 63-65.
} 
Como vemos, las expectativas del inversor extranjero respecto del recurso tierra son mucho más particulares y detalladas que producir productos agrícolas. Un plan de inversión y el beneficio esperado no dependen solamente de tener el control físico sobre la tierra. Esta posición es compartida por los tribunales de inversiones. En Burlington c. Ecuador, por ejemplo, los árbitros explicaron:

When a measure affects the environment or conditions under which the investor carries on its business, what appears to be decisive, in assessing whether there is a substantial deprivation, is the loss of the economic value or economic viability of the investment. In this sense, some tribunals have focused on the use and enjoyment of property. The loss of viability does not necessarily imply a loss of management or control. What matters is the capacity to earn a commercial return. After all, investors make investments to earn a return. If they lose this possibility as a result of a State measure, then they have lost the economic use of their investment. ${ }^{14}$

Jurídicamente, el conjunto de derechos y expectativas que giran alrededor de la propiedad de la tierra describe el dominio que tiene el propietario, ya sea un inversor extranjero o nacional. El conjunto de estos derechos se denomina en la teoría anglosajona de la propiedad el bundle of rights. ${ }^{15} \mathrm{La}$ literatura en historia económica, economía y sociología económica ha destacado la importancia del contenido y la certidumbre de los derechos de propiedad para realizar actividades económicas. Lo que facilita la actividad económica no son los derechos de propiedad en abstracto, sino cierta definición del bundle of rights que permite a los individuos planificar y desarrollar sus inversiones. En este sentido, Douglass North considera que los Estados promueven el crecimiento al definir y hacer cumplir los derechos de propiedad. ${ }^{16}$ Elinor Ostrom, por su parte, sostiene que los derechos de propiedad deben estar adecuadamente definidos para permitir la realización de actividades económicas. ${ }^{17} \mathrm{Y}$ el mismo

14 Burlington c. Ecuador, Icsid Case $\mathrm{N}^{\circ} \mathrm{ARB} / 08 / 5$, decision on liability, 14 de diciembre de 2012, para. 397.

15 Honoré, Anthony, “Ownership”, en Guest, A. G. (Ed.), Oxford essays in jurisprudence: a collaborative work, Oxford University Press, London, New York, 1961, pp. 107-47.

16 North, Douglas, Structure and change in economic history, W. W. Norton \& Company, New York, 1981, p. 21.

17 Ostrom, Elinor \& Schlager, Edella, "The formation of property rights", en Hanna, Susan; Folke, Carl \& Mäler, Karl-Göran (Eds.), Rights to nature: ecological, economic, cultural, 
Max Weber desarrolló todo su análisis respecto del rol del orden jurídico en la promoción del capitalismo a partir de la forma en que los derechos brindan poder de control sobre los recursos. ${ }^{18}$

En la práctica, este control depende de una larga serie de factores y no simplemente del texto de la legislación. El control que otorgan los derechos de propiedad sobre los recursos es una variable de, principalmente, dos elementos: la definición legal y la interpretación que hacen los jueces o árbitros en disputas concretas. La legislación puede establecer expresamente que el inversor extranjero puede hacer con la tierra cuanto desee. No obstante, si los jueces continuamente deciden que ello está sujeto a, por ejemplo, una función social, el contenido del derecho de propiedad individual - $\mathrm{y}$ el control que otorga - puede quedar reducido considerablemente. En una palabra, como enseña Karl Llewellyn, "[n]ot only 'no remedy no right', but 'precisely as much right as remedy". ${ }^{19}$

No obstante, la mayoría de la literatura sobre protección de inversiones extranjeras ha omitido analizar en detalle el rol de los árbitros en la determinación del contenido de los derechos de los inversores extranjeros. Como señalo en la introducción, los grandes temas del régimen internacional de inversiones para casi todos los autores son el procedimiento del arbitraje internacional de inversiones, los árbitros de inversiones y la expropiación indirecta y el trato justo y equitativo. Los inversores extranjeros, sin embargo, están interesados en la protección de sus inversiones en la medida que ello les permite mantener el control necesario sobre los recursos para alcanzar sus expectativas de negocios. No se trata de proteger derechos en abstracto. En este sentido, una pregunta que ha recibido poca atención en la literatura, pero que es fundamental, es la determinación de los derechos contenidos en el bundle of rights del inversor extranjero. La determinación de que un Estado ha expropiado o afectado los derechos de un inversor extranjero requiere primero establecer el contenido de esos derechos. ${ }^{20}$

and political principles of institutions for the environment, Island Press, Washington D.C., 1996, p. 137.

18 Weber, Max, Economy and society, editado por Guenther Roth y Claus Wittich, Bedminster Press, New York, 1968, vol. 1, p. 68.

19 Llewellyn, Karl, Jurisprudence: realism in theory and practice, Transaction Publishers, New Brunswick, London, 2000, p. 63.

20 Rose, Carol, 'Takings' and the practices of property: property as wealth, property as 'propriety", en Property and persuasion, Westview Press, Colorado, 1994, p. 50; Michelman, 


\subsection{Las tres dimensiones de los derechos de propiedad y la indeterminación del 'bundle of rights'}

Los derechos de propiedad privada tienen un contenido complejo que consta no de una, sino de tres dimensiones diferentes que tienen un único objetivo: definir que ciertos recursos están en manos de un individuo, y que este individuo puede decidir su uso. ${ }^{21} \mathrm{La}$ primera dimensión se refiere a la alienabilidad de los recursos. Es un error pensar que todos los recursos que existen en la naturaleza pueden ser objeto de derechos de propiedad privada. Durante gran parte de la historia humana, las ideas no eran apropiables; por otro lado, solo desde hace dos siglos está prohibido adquirir derechos de propiedad sobre personas. La decisión de que ciertos recursos pueden ser adquiridos por individuos es muy importante para cualquier comunidad. ${ }^{22}$ A los fines de este trabajo, es importante destacar que la mayoría de las legislaciones nacionales no permite a los individuos adquirir derechos de propiedad sobre grandes recursos hídricos. Esta es una cuestión muy importante para las inversiones extranjeras en agricultura, dado el rol fundamental del recurso agua. Los órdenes jurídicos nacionales tienen normas diferentes respecto de los recursos hídricos que pueden pertenecer al propietario de la tierra adyacente, o los que por su envergadura quedan bajo el control de los Estados. ${ }^{23}$

La segunda dimensión de los derechos de propiedad privada sirve para determinar el individuo o individuos que son propietarios del recurso. Esta dimensión es muy importante para el funcionamiento del mercado. Para que los mercados funcionen con costos de transacción aceptables, es necesario que las personas tengan seguridad sobre la titularidad del

Frank, "Property as a constitutional right", Washington and Lee Law Review, 1981, 38, pp. 1098-1099.

21 Sherwin, Emily, "Two-and three- dimensional property rights", Arizona Law Review, 1997, 29, pp. 1084, 1087, 1090.

22 Penner, James, The idea of property in law, Oxford University Press, Oxford, 2000, pp. 5-6.

23 Schulz, Clifford \& Weber, Gregory, "Changing judicial attitudes towards property rights in California water resources: from vested rights to utilitarian reallocations", Pacific Law Journal, 1987, 19, pp. 1031-1110; Alexander, Gregory, The global debate over constitutional property: lessons for American takings jurisprudence, University of Chicago Press, Chicago, 2006, pp. 139-147. 
recurso. ${ }^{24}$ La certidumbre sobre la titularidad también es muy importante a los fines de facilitar el uso del recurso, principalmente de la tierra. Cuando existen dudas sobre quién es el propietario del recurso, se desatan conflictos que impiden el uso pacífico de la tierra. Distintos grupos pelean por ejercer un control que ellos consideran legítimo. Justamente, lo que hacen los sistemas de registro sobre la tierra es publicitar a toda la comunidad la identidad del o de los sujetos que pueden ejercer el control de los recursos según los límites establecidos por la ley.

El orden jurídico establece estas dimensiones con un gran nivel de certidumbre. La legislación generalmente es poco vaga o ambigua respecto de la posibilidad de adquirir derechos de propiedad sobre un recurso. La ley suele aclarar expresamente cualquier imposibilidad para adquirir derechos de propiedad sobre ciertas tierras o ciertos espacios de agua. Al mismo tiempo, los sistemas registrales suelen dar gran certidumbre respecto de la titularidad de la tierra. La mayoría de estos sistemas establecen mayores requisitos y, por ende, brindan más certidumbre en relación con derechos inmobiliarios. Si bien es posible que surjan dificultades en relación con la posibilidad de adquirir una porción de tierra, o con la titularidad de un área concreta de tierra, es razonable concluir que regímenes sofisticados de propiedad privada limitarían estas incertidumbres al mínimo.

El principio que rige la tercera dimensión de los derechos de propiedad es precisamente el opuesto. Ni el más sofisticado de los regímenes de propiedad privada puede otorgar certidumbre sobre todos los posibles usos y derechos que conforman el bundle of rights. ${ }^{25} \mathrm{El}$ dominio o control del recurso tierra agrícola es incompleto por varias razones. Primero, la tecnología modifica la forma en que pueden ser usados los recursos. Hace 50 años era impensable contar con semillas genéticamente modificadas. En este período, lo que sucedió es que ha habido un proceso político y regulatorio donde los diferentes órganos del Estado han ido permitiendo, o limitando, el uso de estas tecnologías. Segundo, es imposible asumir que estas decisiones jamás serán revisadas. Las leyes no son para siempre. El principio democrático de gobierno asume que puede haber cambios. ${ }^{26}$

24 Merrill, Thomas \& Smith, Henry, "Optimal standardization in the law of property: the numerus clausus principle", Yale Law Journal, 2000, 110, pp. 68-69.

25 Barrère, Christian, "Judicial system and property rights", en Colombatto, Enrico (Ed.), The Elgar Companion to the economics of property rights, Edward Elgar Pub., Cheltenham, 2006, p. 129.

26 Waldron, Jeremy, The rule of law and the measure of property, Cambridge University Press, Cambridge, 2012, pp. 104-109. 
Es cierto que estos cambios están limitados procedimental y sustancialmente, sin embargo, el espacio de transformación que existe sin pagar compensaciones es una cuestión siempre debatible. Este es uno de los motivos por los que la jurisprudencia de los Estados Unidos sobre expropiaciones indirectas ha sido caracterizada como un pantanal o "muddle". ${ }^{27}$

Tercero, sucede que ningún orden jurídico puede enumerar en forma exhaustiva y con precisión cada uno de los usos y derechos que tienen los propietarios. Las legislaciones, en general, establecen que el titular puede disfrutar del uso del recurso y hacerse de sus frutos. Esta definición es imprecisa y abstracta para el inversor cuyo interés es utilizar el recurso de una forma concreta para alcanzar sus expectativas. La norma general que rige el uso de los recursos otorgado por los derechos de propiedad es el principio de clausura. El individuo puede usar el recurso como lo desee, y hacerse de los beneficios, siembre que el uso esté permitido por la ley. En este caso, por ejemplo, si el individuo utiliza semillas genéticamente modificadas porque ello no está expresamente prohibido, esto no significa que ha adquirido un derecho. Se trata de un mero uso. Sin embargo, el orden jurídico también otorga derechos sobre ciertos usos al propietario de la tierra. En este caso, se tratará de un derecho adquirido o de un uso legal. Los derechos adquiridos son el producto no solo de normas positivas, sino también de usos y prácticas sociales. ${ }^{28} \mathrm{~A}$ diferencia de un mero uso, los derechos adquiridos no pueden ser revocados sin pagar compensación.

En la práctica, la distinción entre un mero uso y un derecho adquirido es compleja y depende de la interpretación que hagan los jueces de las leyes, los actos administrativos y las prácticas sociales. Esta cuestión fue abordada a nivel internacional por el primer relator de responsabilidad de los Estados, Francisco García Amador, en el marco de la Comisión de Derecho Internacional. ${ }^{29}$ En virtud de estas dificultades interpretativas, es común que las inversiones extranjeras a largo plazo se establezcan solo tras obtener garantías contractuales de los Estados sobre el uso de los recursos, o permisos o licencias que garanticen la posibilidad de realizar

27 Rose, Carol, "Mahon reconstructed: why the takings issue is still a muddle", Southern California Law Review, 1984, 57, pp. 561-599; Rose-Ackerman, Susan, "Against ad hocery: a comment on Michelman”, Columbia Law Review, 1988, 88, pp. 1697-1711.

28 Cole, Daniel \& Grossman, Peter, “The meaning of property rights: law versus economics?", Land Economics, 2002, 78, (3), p. 322.

29 Ver García Amador, Francisco, International responsibility. Fourth report, Comisión de Derecho Internacional, A/CN.4/119, 1959. 
la actividad por un período concreto. ${ }^{30}$ Estos contratos y permisos son actos jurídicos que tienen una relación estrecha con el derecho de propiedad sobre el recurso. ${ }^{31}$ No se trata de un típico contrato donde dos partes intercambian prestaciones, sino de la adquisición por parte del inversor extranjero de certidumbre respecto de las condiciones de explotación de ciertos recursos.

Es razonable que los inversores extranjeros, y también los nacionales, tengan un incentivo a obtener estos contratos. No obstante, no siempre los obtienen, y, cuando lo hacen, esto no significa que queden cubiertos todos los posibles cambios en un régimen jurídico. Estos derechos especiales no necesariamente cubren todos los aspectos referidos a la inversión. Un permiso para utilizar semillas genéticamente modificadas no incluiría, por ejemplo, la posibilidad de exportar la producción. Esta incertidumbre o falta de precisión en el orden jurídico puede permanecer inadvertida hasta cuando se desata un conflicto. Es en ese contexto que los árbitros internacionales deben intervenir y resolver si el inversor extranjero realmente tiene derecho a exportar el producto (gozar del precio internacional), a utilizar semillas genéticamente modificadas o a usar ciertos recursos hídricos. ${ }^{32}$

\subsection{Los derechos de propiedad de los inversores extranjeros frente a los inversores nacionales}

La premisa central de este trabajo es que los TPIE tienen efectos en los derechos de los inversores extranjeros sobre la tierra en el marco de proyectos agrícolas. Dado que el principal interés de los inversores extranjeros por la protección internacional se refiere al mantenimiento de las condiciones necesarias para realizar sus expectativas de negocio, la pregunta es si la

\footnotetext{
30 Ver Shemberg, Andrea, Stabilization clauses and buman rights, International Finance Corporation and the United Nations Special Representative to the Secretary General on Business and Human Rights, 2008.

31 Douglas, Zachary, "The hybrid foundations of investment treaty arbitration", British Yearbook of International Law, 2003, 74, p. 197.

32 Ver Paulsson, Jan, "Universal arbitration - what we gain, what we lose", The Alexander Lecture - Chartered Institute of Arbitrators, 29 de noviembre de 2012 (draft: 3 de diciembre de 2012), p. 10, en http://www.globalarbitrationreview.com/cdn/files/gar/articles/ jan_Paulsson_Universal_Arbitration_-_what_we_gain_what_we_lose.pdf, consulta del $1^{\circ}$ de febrero de 2015.
} 
aplicación de esta protección vuelve a la definición de sus derechos más acorde con estas expectativas. Si así fuera, es razonable suponer que los derechos de propiedad de los inversores extranjeros sobre la tierra podrían ser diferentes de los adquiridos por nacionales sobre el mismo recurso. A simple vista, la diferencia entre el inversor nacional y el extranjero sería solo que los primeros deben resolver sus conflictos con los Estados a través de los tribunales nacionales, mientras que los segundos pueden acudir a un arbitraje de inversiones. ${ }^{33}$ Sin embargo, un remedio distinto tiene efectos sobre el contenido del derecho, precisamente porque "as much right as remedy".

La primera y segunda dimensiones de los derechos de propiedad están generalmente bien definidas en el orden jurídico del Estado que recibe la inversión. Si bien pueden surgir algunas dudas, se trataría en general de cuestiones de hecho. Los TPIE no establecen reglas respecto de los recursos que pueden ser alienables o de los mecanismos que determinan la titularidad. Por el contrario, gran parte de los tratados establecen expresamente que la inversión extranjera solo es válida en la medida que se haya radicado de acuerdo con la ley del Estado receptor. ${ }^{34}$ De esta forma, como las dos primeras dimensiones de los derechos de propiedad son relativamente claras, y los TPIE expresa o implícitamente establecen que la inversión debe establecerse conforme con la legislación nacional, es posible concluir que los inversores extranjeros están en este respecto en pie de igualdad con los nacionales. En este sentido, el tribunal en Bayview Irrigation c. México consideró que "it is plain that under the Mexican Constitution and Mexican law, the Claimants could have no such property rights in water in Mexican rivers". 35

Esto es muy distinto respecto de la tercera dimensión o el control que los derechos de propiedad otorgan a los inversores extranjeros. Como los árbitros internacionales definen el contenido de los derechos en casos de vaguedad o ambigüedad, lo que es la regla y no la excepción, la interpretación que hacen puede tener efectos importantes. Aquí no existen reglas expresas que establezcan claramente cuándo el inversor

\footnotetext{
33 Ver el desarrollo del tema en Cotula, Lorenzo, "The new enclosures? Polanyi, international investment law and the global land rush", Third World Quarterly, 2013, 34, p. 1605.

34 Unctad, Bilateral investment treaties 1995-2006: trends in investment rulemaking, Naciones Unidas, Nueva York y Ginebra, 2007, p. 8.

35 Bayview Irrigation c. México, Icsid Case $\mathrm{N}^{\mathrm{o}} \mathrm{ARB}(\mathrm{AF}) / 05 / 1$, award, 19 de junio de 2007, para. 118.
} 
tiene un mero uso o un derecho adquirido. Es siempre materia de interpretación. Al respecto, el consenso en el área de derecho internacional de inversiones es que se aplica la doctrina de expectativas legítimas de acuerdo con el derecho internacional. ${ }^{36}$ Esto significa que los arbitrajes internacionales usan una fórmula especial para definir justamente lo que más preocupa a los inversores extranjeros: el control sobre los recursos. El régimen internacional de inversiones, de esta forma, ejecutaría la protección incluida en los TPIE sobre una medida de derechos de propiedad que no coincide necesariamente con la que tendría un inversor nacional en las mismas circunstancias. ${ }^{37}$ Los tribunales de inversiones tienen dicho en varias oportunidades que las expectativas legítimas deben ser consideradas conforme al derecho internacional. ${ }^{38}$ La diferencia entre el derecho de un inversor extranjero y nacional, en pocas palabras, es precisamente la aplicación de esta fórmula interpretativa, aunque, más allá de su nombre, lo que importa es su aplicación y sus efectos concretos sobre los derechos de los inversores extranjeros.

\section{La fórmula de las expectativas legítimas y los derechos de propiedad de los inversores extranjeros}

El objetivo de esta segunda parte es describir los efectos de la fórmula que utilizan los tribunales arbitrales internacionales para determinar el bundle of rights de los inversores extranjeros. La definición del contenido de sus derechos es fundamental a la hora de decidir si un Estado debe pagar compensación por una medida. Si el inversor extranjero nunca tuvo un derecho adquirido a exportar la producción, por ejemplo, la prohibición de que lo siga haciendo no crearía obligación de pagar compensación.

\footnotetext{
36 Perrone, Nicolás, supra nota 7, pp. 415-6.

37 Ver Sornarajah, M., "The case against a regime on international investment law", en Trakman, Leon \& Ranieri, Nick (Eds.), Regionalism in international investment law, Oxford University Press, New York, 2013, p. 494; Schneiderman, David, Constitutionalizing economic globalization. Investment rules and democracy's promise, Cambridge University Press, New York, 2008; Van Harten, Gus, Investment treaty arbitration and public law, Oxford University Press, New York, 2007.

38 Total c. Argentina, Icsid Case No ARB/04/01, decision on liability, 27 de diciembre de 2010, para. 128; LG\&E c. Argentina, Icsid Case $\mathrm{N}^{\circ} \mathrm{ARB} / 02 / 1$, decision on liability, 3 de octubre de 2006, para. 130; OKO v. Estonia, Icsid Case $\mathrm{N}^{\mathrm{O}} \mathrm{ARB} / 04 / 6$, award, 19 de noviembre de 2007, para. 274.
} 
Desde finales de la década de los noventa, la práctica del arbitraje de inversiones muestra una reducción considerable de condenas por expropiaciones indirectas, y un aumento de las condenas por violación del trato justo y equitativo. ${ }^{39}$ Luego de algunos casos aislados a principios de los años dos mil, existe hoy cierto consenso de que las regulaciones difícilmente pueden constituir expropiaciones. ${ }^{40}$ Actualmente, el estándar para determinar una expropiación indirecta es muy alto, y las medidas regulatorias casi nunca desapoderan completamente al inversor extranjero. ${ }^{41}$ Gran parte de las medidas estatales, de esta forma, no constituye una expropiación aunque el inversor extranjero no pueda continuar desarrollando la actividad de la misma forma u obtener el mismo beneficio. Estas medidas, sin embargo, sí pueden constituir violaciones del trato justo y equitativo. Este giro de las expropiaciones indirectas hacia el trato justo y equitativo coincide con la tendencia según la cual las expectativas legítimas dejaron de ser consideradas al analizarse el caso por expropiación, y solo se analizan bajo el estándar del trato justo y equitativo. Si bien esto no fue siempre así, como explica Stephen Fietta, ${ }^{42}$ lo importante es que las expectativas legítimas bajo el amparo de la cláusula de trato justo y equitativo se transformaron en la piedra angular del sistema, como señala Thomas Wälde en una influyente decisión. ${ }^{43}$

Los árbitros de inversiones utilizan la fórmula de las expectativas legítimas para definir el contenido de los derechos de propiedad del inversor extranjero. ${ }^{44}$ Cuando la legislación es oscura respecto de este contenido, y no existen contratos o permisos que definen el punto expresamente, los árbitros deben interpretar los derechos de los inversores extranjeros. Por

39 Bernasconi-Osterwalder, Nathalie \& Vyoma, Jha, Recent developments in international investment disputes: investment treaty cases from September 2010 to October 2011, International Institute for Sustainable Development, 2012, p. 11.

40 SD Myers c. Canadá, Uncitral-Nafta, partial award, 13 de noviembre de 2000, para. 282.

41 National Grid Plc. c. Argentina, Uncitral, award, 3 de noviembre de 2008, para. 149.

42 Fietta, Stephen, "Expropriation and the 'fair and equitable' standard", Journal of International Arbitration, 2006, 23, (5), pp. 379-381.

43 International Thunderbird c. México, Nafta-Uncitral, opinión de Thomas Wälde, $1^{\circ}$ de diciembre de 2005, para. 37.

44 Gaillard, Emmanuel, "Chronique des sentences arbitrales - Centre International pour le Règlement des Différends Relatifs aux Inves-tissements (Cirdi)", Revue trimestrielle Lexis Nexis Juris Classeur, 2008, pp. 332-334; Von Walter, André, “The investor's expectations in international investment arbitration", Transnational Dispute Management, 2009, 6, (1), p. 6. 
supuesto, si estos y el Estado hubiesen suscripto un contrato estableciendo que el objetivo del proyecto era exportar toda la producción, la cuestión sería mucho más simple. La fórmula de las expectativas legítimas es útil precisamente para los casos difíciles, donde el dominio en abstracto se mantiene en manos del inversor extranjero — no ha sido desapoderado—, pero han ocurrido cambios legales que afectan su actividad y el beneficio esperado.

La base de la doctrina de las expectativas legítimas es la inversión hecha por el inversor extranjero. Se trata de investment-backed expectations. ${ }^{45}$ A diferencia de lo que ocurre con el concepto de propiedad, el concepto de inversión se centra en la actividad que realiza el inversor a los fines de generar valor y apropiarse del beneficio. ${ }^{46}$ Esta noción es diferente de la idea de propiedad que se centra en la relación del sujeto con el recurso y no en la actividad concreta que este realiza. De esta forma, utilizar el concepto de inversión como base de la doctrina de expectativas legítimas significa colocar el foco no en el control abstracto sobre los recursos, que no interesa al inversor extranjero, sino en el plan de inversión que lo llevó a establecerse en el Estado receptor. Esto tiene por consecuencia una tendencia en favor del reconocimiento de derechos sobre los usos que son necesarios para realizar la inversión y sobre la expectativa de apropiarse del beneficio esperado.

La doctrina de las expectativas legítimas tiene dos componentes interdependientes que definen si el inversor extranjero tiene un derecho que correspondería compensar. ${ }^{47} \mathrm{~A}$ los fines ilustrativos, es posible presentar estos componentes como dos preguntas. La primera pregunta es si el inversor extranjero pudo confiar en declaraciones, incentivos o en la legislación vigente en el Estado receptor a los fines de planificar su proyecto. La segunda pregunta es si el inversor extranjero podía esperar razonablemente que el Estado fuera a mantener la vigencia de las condiciones contenidas en esas declaraciones, incentivos o en la legislación.

El análisis de la primera pregunta se concentra en la posición del inversor extranjero durante el momento previo y la concreción de la inversión extranjera. Los árbitros se concentran en el momento de

45 Glamis c. USA, Uncitral-Nafta, award, 8 de junio de 2009, para. 356.

46 Mandelker, Daniel, "Investment-backed expectations: is there a taking?", Journal of Urban and Contemporary Law, 1987, 31, (3), p. 4.

47 Schønberg, Søren, Legitimate expectations in administrative law, Oxford University Press, New York, 2000, pp. 9-11. 
la inversión. ${ }^{48}$ Este elemento temporal es fundamental para conocer el proyecto del inversor extranjero y en qué medida este confió en actos del Estado para su planificación. El momento de la inversión revela la relación entre el plan del inversor, el control que le otorgaba la legislación y otros actos estatales, y el beneficio que esperaba. Lo que define la creación de expectativas legítimas es si el inversor podía confiar, de manera razonable, en las declaraciones del gobierno o en el orden jurídico del país receptor al momento de invertir. Estas declaraciones, a veces llamadas incentivos, no son concesiones específicas establecidas en contratos. Por el contrario, son acciones dirigidas a convencer al inversor extranjero para que invierta en el país. Cualquier gobierno puede mencionar los beneficios que otorga la ley vigente, pero no por ello se obligaría a no modificar la normativa. Algo parecido podría pasar del lado del inversor extranjero, este puede sugerir al Estado que el proyecto va a generar tantos puestos de trabajo, tanta exportación, tal nivel de actividad, etcétera. Sin embargo, es debatible que por ello el inversor extranjero quede legalmente obligado a crear esa cantidad de fuentes de trabajo.

En este marco, la función de la fórmula de las expectativas legítimas es calificar algunas de las declaraciones hechas por el gobierno del Estado receptor como representaciones que generan derechos en el inversor extranjero cuando este confió en ellas para invertir. Por un lado, estas declaraciones a veces pueden estar mucho más cerca de constituir derechos que por algún motivo no fueron formalizados en un contrato, una licencia o un permiso. Pero, por otro lado, los laudos arbitrales han considerado que las representaciones dadas por el Estado pueden ser tanto expresas como implícitas. ${ }^{49}$ Los tribunales han admitido que las expectativas pueden surgir de una reunión de negocios, de tratativas, o que también puede emanar - aunque con un grado menor- de la legislación del país receptor. ${ }^{50}$ Esto explicaría porque los laudos arbitrales hacen importantes

48 Schreuer, Christoph \& Kriebaum, Ursula, "At what time must legitimate expectations exist?”, en Werner, Jacques \& Ali, Arif (Eds.), A liber amicorum: Thomas Wälde, CMP Publishing Ltd, London, 2009, p. 265.

49 Total c. Argentina, Icsid Case No ARB/04/01, decision on liability, 27 de diciembre de 2010, para. 120.

50 Continental c. Argentina, Icsid Case No ARB/03/9, award, 5 de septiembre de 2008, para. 261; El Paso c. Argentina, Icsid Case No ARB/03/15, award, 31 de octubre de 2011, para. 378. 
consideraciones sobre los hechos de una controversia. ${ }^{51}$ La cuestión fundamental es analizar los hechos para determinar si el inversor extranjero pudo o no confiar en las declaraciones, los incentivos o la legislación del Estado receptor.

Dentro de este marco interpretativo, vale destacar que el inversor extranjero tiene que haber sido razonable al confiar en esas declaraciones. Al ser una cuestión de hecho, es muy difícil predecir la manera en que los tribunales pueden valorar este requisito. Existe consenso, no obstante, en que los TPIE no son garantías para el inversor extranjero de que el proyecto será exitoso y conseguirá el beneficio esperado. ${ }^{52}$ En el mismo sentido, los tribunales han considerado que los inversores extranjeros deben ser conscientes de la realidad económica y social del país donde invierten. ${ }^{53} \mathrm{La}$ razonabilidad del inversor es un factor que puede minimizar la expansión de los derechos a partir de la doctrina de las expectativas legítimas. Pero este elemento es parte de una doctrina que sirve para otorgar derechos al inversor extranjero sin focalizarse en la intención del Estado receptor de obligarse. ${ }^{54} \mathrm{La}$ intención del Estado pasa a ser secundaria, así como la existencia de un acto jurídico concreto - sea un contrato o un permisoque defina el derecho del inversor extranjero más allá de la legislación doméstica. En este sentido, la crítica de Pedro Nikken en su voto disidente en Suez. c. Argentina parece acertada. ${ }^{55}$

La segunda pregunta que consideran los tribunales de inversiones es la medida en que el inversor extranjero puede esperar que las bases regulatorias de su emprendimiento y del beneficio esperado se mantendrán en el tiempo. La formulación de esta pregunta parte de la premisa de que el inversor extranjero no tiene un derecho que lo protege de cualquier modificación de las leyes. ${ }^{56} \mathrm{El}$ punto de partida no es que cualquier cam-

51 Spyridon Roussalis c. Romania, Icsid Case $\mathrm{N}^{\circ}$ ARB/06/1, award, 7 de diciembre de 2011, para. 318; Merrill c. Canadá, Uncitral, Icsid Administered Case - Nafta, award, 31 de marzo de 2010, para. 210.

52 Maffezini c. Spain, Icsid Case $\mathrm{N}^{\circ}$ ARB/97/7, award, 13 de noviembre de 2000, para 64.

53 Duke c. Ecuador, Icsid Case No ARB/04/19, award, 18 de agosto de 2008, para. 340.

54 Gold, Andrew, "A property theory of contract", Northwestern University Law Review, 2009, 103 (1), pp. 19-24.

55 Ver Suez. Argentina, Icsid Case No ARB/03/17, opinión de Pedro Nikken, 30 de julio de 2010.

56 El Paso c. Argentina, Icsid Case No ARB/03/15, award, 31 de octubre de 2011, para. 352; EDF c. Rumania, Icsid Case No ARB/05/13, award, 8 de octubre de 2009, para. 218. 
bio que afecte su plan de inversiones genera la obligación de pagar una compensación, sino que hay cambios que son más proclives a requerir compensaciones que otros, dependiendo de si el inversor extranjero podía preverlos. En este sentido, el tribunal en el caso Frontier c. República Checa consideró: "While the host state is entitled to determine its legal and economic order, the investor also has a legitimate expectation in the system's stability to facilitate rational planning and decision making". 57

Dado que los laudos arbitrales abandonaron la postura en favor de la estabilidad del orden jurídico, la cuestión por debatir son las circunstancias en que el inversor extranjero debe tolerar los cambios y cuándo debe recibir una compensación. Los tribunales han considerado que los cambios deben respetar ciertos requisitos de procedimiento, principalmente deben ser transparentes y no discriminatorios. Estos requisitos son muy importantes para el inversor extranjero, sin embargo, su problema es qué medidas transparentes y no discriminatorias pueden afectar su emprendimiento considerablemente. Los tribunales de inversiones no son indiferentes al respecto, afirmando que los cambios implementados por los Estados también deben ser consistentes. ${ }^{58}$

Esto quiere decir que las expectativas de los inversores no impiden cualquier cambio, sino solo cambios de carácter más drástico, que el inversor no podría haber previsto al momento de invertir en virtud de las declaraciones hechas por el Estado. La línea que siguen los laudos en este sentido es relativamente consistente. En la medida que los cambios realizados por el Estado responden a las pautas regulatorias existentes al momento de la inversión, es difícil que el Estado vea comprometida su responsabilidad. ${ }^{59} \mathrm{Al}$ mismo tiempo, si los cambios obedecen a externalidades negativas del inversor extranjero, los laudos tienden a dar la razón a los Estados. ${ }^{60} \mathrm{El}$ razonamiento detrás de estos casos es que el inversor extranjero podía prever que, si su actividad no respetaba la regulación existente al momento de establecerse, su inversión podía no llegar a buen

57 Frontier Petroleum c. República Checa, Uncitral, award, 12 de noviembre de 2010, para. 285.

58 Saluka c. República Checa, Uncitral, partial award, 17 de marzo de 2006, para. 307; Ioannis Kardassopoulos c. Georgia, Icsid Case No ARB/05/18, award, 3 de marzo de 2010, para. 438. 59 Genin c. Estonia, Icsid Case No ARB/99/2, award, 25 de junio de 2001, para. 370.

60 Methanex c. USA, Uncitral-Nafta, final award of the Tribunal on Jurisdiction and Merits, 3 de agosto de 2005, parte III.A; Chemtura c. Canadá, Uncitral-Nafta, award, 2 de agosto de 2010, paras. 124-225; Glamis c. USA, Uncitral-Nafta, award, 8 de junio de 2009, parte II y pars. $756-829$. 
puerto. Lo mismo ocurre en relación con la determinación de las externalidades negativas a partir de análisis científicos. El inversor extranjero no puede esperar que el Estado no haga nada respecto de los efectos negativos que produce su actividad.

La balanza comienza a favorecer al inversor extranjero si los cambios implementados implican un cambio del paradigma regulatorio, ${ }^{61}$ son el producto de un cambio de política o la respuesta a nuevas preferencias de la comunidad. ${ }^{62}$ Según el razonamiento de los tribunales, las expectativas del inversor extranjero sufren en estas circunstancias por partida doble. Por un lado, este tipo de cambios suele tener efectos más amplios sobre el plan de negocios del inversor extranjero. Una cosa es tener que adaptarse a nuevas condiciones regulatorias en un marco de continuidad, y otra cosa es sufrir cambios más profundos que impactan en el esquema de negocios y el beneficio esperado. Por el otro, los cambios regulatorios basados en evidencia científica serían más predecibles para el inversor extranjero. No ocurre lo mismo con cambios que obedecen a preferencias políticas o sociales, porque estos están más alejados del control del inversor extranjero. Al momento de invertir, es razonable que el inversor asuma que el Estado actuará si no cumple con las pautas regulatorias o si su actividad resulta dañina para la población. Para los tribunales arbitrales, es menos razonable que asuma que su proyecto de inversión puede ser alterado por cambios basados en nuevas preferencias sociales o políticas.

\section{Los derechos de los inversores extranjeros sobre la tierra según los TPIE: efectos para la política pública}

El objetivo de esta última parte es explorar algunos efectos concretos que la fórmula de las expectativas legítimas tiene en el bundle of rights de los inversores extranjeros sobre la tierra y los emprendimientos agrícolas. Desde el punto de vista de cualquier Estado constitucional, existen dos grandes requisitos para realizar cambios en la legislación y regulación. Primero, el Estado debe respetar los pasos procedimentales que permiten a los individuos afectados hacer conocer su posición, presentar información

\footnotetext{
61 Total c. Argentina, Icsid Case No ARB/04/01, decision on liability, 27 de diciembre de 2010, para. 333; El Paso c. Argentina, Icsid Case No ARB/03/15, award, 31 de octubre de 2011, para. 510.

62 Tecmed c. México, Icsid Case $\mathrm{N}^{\circ} \mathrm{ARB}(\mathrm{AF}) / 00 / 2$, award, 29 de mayo de 2003, paras. 127-133.
} 
y peticionar ante las autoridades. Caso contrario, los sujetos que vieron vulnerados sus derechos pueden recurrir a las medidas judicialmente. Segundo, en un régimen constitucional de propiedad, incluyendo en este marco al régimen internacional de inversiones, los Estados también tienen limitaciones sustanciales. Entre ellas, se encuentran los derechos de propiedad, así como cualquier contrato o permiso. El Estado debe compensar a cualquier inversor si lo desapodera de la tierra para redistribuirla o utilizarla para otros fines. Pero, obviamente, este es el caso más fácil y en la mayoría de los países inversores nacionales y extranjeros están en las mismas condiciones respecto de expropiaciones directas (con la excepción del monto de la compensación).

La gran diferencia entre los inversores extranjeros y los nacionales comienza a partir de que los primeros pueden acceder a un arbitraje de inversiones a los efectos de ejecutar la protección otorgada por los TPIE. Como se explicó, no obstante, esta diferencia tiene efectos más allá de la mera ejecución de los derechos. A continuación, se ilustra esta premisa en relación con la posición preferencial que tendrían los inversores extranjeros en cinco escenarios distintos.

\subsection{El derecho a exportar la producción o al precio de exportación frente a medidas comerciales y tributarias}

Muchos de los inversores extranjeros que se establecen en países agrícolas con el objetivo de producir commodities lo hacen para exportar. Como mencioné en la primera parte de este trabajo, los inversores extranjeros privados tienen en general su expectativa puesta en el precio internacional, mientras que los inversores extranjeros públicos tienen expectativas respecto del abastecimiento de su país de origen. En este sentido, existen antecedentes en el régimen de inversiones del Tratado de Libre Comercio de América del Norte (TLCAN), donde inversores de los Estados Unidos demandaron a Canadá por la limitación de exportaciones o por la falta de acceso al precio internacional. Estos casos son relevantes para el sector agrícola, porque se referían a la exportación de otro commodity: la madera. El tribunal en Pope \&o Talbot c. Canadá consideró que el inversor extranjero tenía el derecho a exportar la producción, ${ }^{63}$ y, finalmente condenó a Canadá por otras razones vinculadas. Esta decisión generó bastante debate en

63 Pope \& Talbot c. Canadá, Uncitral-Nafta, interim award, 26 de junio de 2000, para. 96. 
el marco del TLCAN y los tres países socios elaboraron una interpretación obligatoria que apuntaba a alterar la fórmula de las expectativas legítimas. La premisa de esta interpretación es que el capítulo 11 del TLCAN no brinda el estándar de trato justo y equitativo, sino solo el trato mínimo conforme al derecho internacional. Luego de esta decisión, el tribunal arbitral en Merrill c. Canadá decidió en un caso similar que Canadá no había hecho declaración o representación alguna sobre la exportación o el precio de venta de la producción. ${ }^{64}$ Respecto del estándar aplicable, este tribunal se sujetó a la interpretación obligatoria, es decir, utilizó el trato mínimo, destacando, sin embargo, que en la práctica el estándar de trato mínimo es muy similar al trato justo y equitativo.

A los fines de analizar una posible demanda arbitral por el derecho a exportar o a cobrar el precio internacional, es necesario tener presente dos cosas. Primero, lo más probable es que un tribunal de inversiones aplique el estándar de trato justo y equitativo. En el caso latinoamericano, existe una gran cantidad de tratados de primera generación vigentes que se refieren expresamente al trato justo y equitativo. En una disputa concreta, por supuesto, esto dependerá del texto del tratado aplicable y de la postura de los árbitros. Por ahora, esta discusión solo ha ocurrido en el TLCAN, y la postura parecería ser que en la práctica no existiría una gran diferencia entre estos estándares..$^{65}$ Sin perjuicio de esta aparente semejanza, no puede descartarse que la aplicación de uno u otro estándar pueda tener implicancias en casos concretos. ${ }^{66}$

Segundo, lo más importante es considerar la posición del inversor extranjero al invertir, teniendo en cuenta las declaraciones que hubiera hecho el gobierno del país receptor y el contenido de su orden jurídico en ese momento. Las leyes generales solo pueden generar expectativas reducidas, mientras que las declaraciones podrían otorgar expectativas más considerables. ${ }^{67}$ En este marco, un inversor extranjero que invierte para producir un bien históricamente de exportación en el país receptor tendría argumentos para defender sus expectativas legítimas de exportar

${ }^{64}$ Merrill c. Canadá, Uncitral, Icsid Administered Case - Nafta, award, 31 de marzo de 2010, para. 142.

65 Pope \& Talbot c. Canadá, Uncitral-Nafta, award in respect of damages, 31 de mayo de 2002, paras. 59-65.

66 Ibíd., para. 65.

${ }^{67}$ Continental c. Argentina, Icsid Case No ARB/03/9, award, 5 de septiembre de 2008, para. 261; ElPaso c. Argentina, Icsid Case No ARB/03/15, award, 31 de octubre de 2011, para. 378. 
la producción. Esto no quita que ciertas restricciones puedan ser consideradas razonables. En materia impositiva, por ejemplo, la creación de impuestos sobre el valor de exportación sería esperable para el inversor, ya que los Estados tienen la potestad de hacer uso de su poder tributario. La controversia podría surgir, no obstante, a partir de ciertos niveles de tributación que habilitarían al inversor a demandar por la frustración de su expectativa legítima al beneficio esperado de su inversión. ${ }^{68}$

\subsection{El derecho a continuar el proyecto frente a cambios dentro del paradigma regulatorio}

Los antecedentes en el ámbito del arbitraje de inversiones parecen señalar que los cambios regulatorios realizados sobre la base del marco existente al momento de la inversión, no afectan las expectativas de los inversores extranjeros. El inversor extranjero solo tiene una expectativa a que los cambios sean consistentes y predecibles. Para los tribunales, es importante la existencia de un proceso administrativo ordenado y transparente, para determinar si el inversor extranjero no puede continuar con cierta actividad o si debe adaptarse a nuevas condiciones. Esta postura surge de dos casos decididos en el marco del TLCAN: Methanex c. Estados Unidos y Glamis c. Estados Unidos. ${ }^{69}$ Según estos antecedentes, vale la pena destacar que no existe la regla de precedente en el arbitraje de inversiones, los tribunales arbitrales de inversiones no condenarían a los Estados por cambios adoptados por los organismos competentes en materia agrícola, siempre que se ajusten al marco regulatorio vigente al momento de la inversión. Es importante, en este sentido, que los cambios regulatorios estén justificados por evidencia científica y que el inversor extranjero haya tenido la oportunidad de participar del procedimiento.

$\mathrm{Al}$ respecto, vale la pena recalcar dos puntos desde la perspectiva latinoamericana. Por un lado, el hecho de que los casos más favorables a la postura de los Estados en casos de regulación por externalidades negativas hayan tenido a los Estados Unidos como demandado genera, al

\footnotetext{
68 Feldman c. México, Icsid Case $\mathrm{N}^{\circ}$ ARB(AF)/99/1, award, 16 de diciembre de 2002, para 106; Sergei Paushoke. . Mongolia, Uncitral, award on jurisdiction and liability, 28 de abril de 2011, paras. 302-303.

69 Methanex c. USA, Uncitral-Nafta, final award of the Tribunal on Jurisdiction and Merits, 3 de agosto de 2005, parte III.A; Glamis c. USA, Uncitral-Nafta, award, 8 de junio de 2009, parte II y paras. $756-829$.
} 
menos, cierta reserva. Existe evidencia de que miembros del gobierno de ese país presionaron a un árbitro para que no fallara en contra de los Estados Unidos porque de otra forma se ponía en riesgo la continuidad del TLCAN. ${ }^{70}$ Por otro lado, los Estados Unidos tienen en materia regulatoria agencias sofisticadas y muy bien equipadas tanto en términos humanos como técnicos. Esto significa que el mismo estándar aplicado a la actividad de los Estados latinoamericanos podría arrojar resultados diferentes.

\subsection{El derecho a continuar el proyecto frente a cambios de política o nuevas preferencias sociales}

En principio, cambios de política o nuevas preferencias de la comunidad tendrían efectos más graves en el control de los inversores extranjeros sobre la tierra agrícola. Es cierto que cambios regulatorios basados en evidencia científica pueden implicar la prohibición de comercializar cierto producto. No obstante, es razonable pensar que las medidas regulatorias tienen un impacto menor sobre la actividad de los actores económicos y, en cualquiera de los casos, serían más consistentes y predecibles. La decisión de cambiar una política o la existencia de nuevas preferencias sociales implica en general cambios más profundos y que son menos esperables - tanto como más externos- para el inversor extranjero. ${ }^{71}$

Los antecedentes que existen en esta materia no favorecen a los Estados receptores de la inversión. En el caso Tecmed c. México, según el tribunal, el gobierno de este país habría generado una expectativa legítima en el inversor extranjero respecto de un proyecto sobre tratamiento de basura, y luego decidió no renovar el permiso sobre la base de una protesta social. Los árbitros no consideraron esta razón favorablemente, y condenaron a México porque las medidas fueron tomadas por presión social y no cumplían con los estándares del TLCAN. ${ }^{72}$ Una postura semejante tomó el tribunal del caso Azurix c. Argentina referido a medidas respecto de la concesión de aguas en la provincia de Buenos Aires. La razón fue

\footnotetext{
70 Stumberg, Robert, Reform of investor protections. Review of the model U.S. bilateral investment treaty, U.s. Department of State \& Office of the U.s. Trade Representative, 29 de julio de 2009, p. 6.

71 Ver al respecto Waldron, Jeremy, supra nota 26, pp. 105-106.

72 Tecmed c. México, Icsid Case $\mathrm{N}^{\mathrm{o}} \mathrm{ARB}(\mathrm{AF}) / 00 / 2$, award, 29 de mayo de 2003, paras. 127-133.
} 
nuevamente que las medidas fueron adoptadas en virtud de una protesta social. ${ }^{73}$ Otro caso similar fue Aguas del Tunari c. Bolivia, donde el gobierno de ese país se vio obligado a dejar sin efecto la concesión para el suministro de agua potable en Cochabamba. Este arbitraje, sin embargo, no llegó a la etapa de resolución, dado que el inversor extranjero retiró la demanda a raíz de la creciente presión internacional. ${ }^{74}$

La distinción entre cambios regulatorios y cambios motivados en preferencias sociales puede ser muy importante en materia agrícola. La base para juzgar las medidas públicas son siempre los derechos de los inversores, sus expectativas según la fórmula utilizada por los árbitros de inversiones. En el marco de estas expectativas, justamente, existiría una gran diferencia si la medida pública es presentada como la respuesta a una externalidad negativa producida por la actividad del inversor extranjero —especialmente si era desconocida al momento de la inversión_-, o como un cambio político, impredecible y ajeno al inversor.

En este marco, vale la pena mencionar que cambios importantes en materia de propiedad intelectual —o la no realización de ciertos cambios- podrían comprometer inversiones en biotecnología, una materia estrechamente conectada a la agricultura. En la medida que empresas dedicadas a la biotecnología pudieran demostrar su carácter de inversores extranjeros, identificando también su inversión en el marco de los TPIE, podrían considerar que sus derechos sobre la propiedad intelectual están siendo vulnerados. En el caso de Colombia, por ejemplo, la situación en que se encuentran los productores de semillas extranjeros en el marco del Tratado de Libre Comercio con los Estados Unidos podría generar alguna responsabilidad para el Estado. Debe recordarse que Colombia ha asumido una obligación internacional de patentar y respetar los derechos de propiedad intelectual sobre semillas. La suspensión de este cambio legislativo, en gran medida, se debió a la importante protesta social ocurrida durante 2013 y principios de $2014 .{ }^{75}$

\footnotetext{
73 Azurix c. Argentina, Icsid Case No ARB/01/12, award, 14 de julio de 2006, para. 378. 74 Aguas del Tunari c. Bolivia, Icsid Case $\mathrm{N}^{\circ} \mathrm{ARB} / 02 / 3$.

75 Ver, entre otros, "Labriegos y defensores de semillas, indignados por decisiones del ICA", en El Tiempo, 30 de noviembre de 2013, en http://www.eltiempo.com/archivo/ documento/ CMS-13236396, consulta del $1^{\circ}$ de febrero de 2015.
} 


\subsection{El derecho a recibir una compensación mayor frente a reformas agrarias o programas de reparación histórica}

En Latinoamérica, la cuestión de la reforma agraria tiene un fuerte antecedente histórico. Los coeficientes de concentración de tierra en la región son los más altos del mundo. ${ }^{76}$ En países como Colombia, además, este tema tiene una gran actualidad en virtud de las negociaciones de paz en La Habana. ${ }^{77}$ Según el orden jurídico de la mayoría de los países de la región, la expropiación de la tierra para su redistribución debe ser compensada. ${ }^{78}$ Los TPIE no innovan sobre este punto, pero pueden tener algunos efectos vinculados al fortalecimiento de los derechos de los inversores extranjeros.

El primer efecto es que estos tratados pueden constituir una excusa del Estado para no avanzar con programas de reforma agraria o de reparación histórica. La situación de la comunidad sawhoyamaxa en Paraguay es un ejemplo de este escenario. Paraguay se había comprometido tanto por sus leyes domésticas como por la Convención Interamericana de Derechos Humanos a devolver a esta comunidad sus tierras históricas. No obstante, el gobierno de este país se negaba a cumplir con las expropiaciones porque las tierras estaban en poder de inversores alemanes que estaban protegidos por un TPIE. En este contexto, la Corte Interamericana de Derechos Humanos ordenó a Paraguay cumplir con sus obligaciones, con el argumento de que la protección de los TPIE debe ser compatible con la Convención Interamericana. ${ }^{79} \mathrm{La}$ razón esgrimida por Paraguay no era atendible porque los TPIE no prohíben la expropiación, sino que la sujetan al pago de una compensación. Sin embargo, los derechos de los inversores extranjeros pueden crear el mismo problema que enfrentó

76 Deininger, Klaus \& Byerlee, Derek, Rising global interest in Farmland: can it yield sustainable and equitable benefits?, World Bank, Washington D.C., 2011, p. 28.

77 Gómez, Andrei; Perrone, Nicolás \& Prieto Ríos, Enrique, "Foreign investors and peace in Colombia", International Community Law Review, forthcoming, LASA Conference, 2015.

78 El artículo 58 de la Constitución de Colombia, tal como fue sancionada en 1991, permitía al Estado expropiar sin pagar compensación. Sin embargo, este artículo fue derogado justamente para lograr la ratificación de tPIE. Ver Prieto Ríos, Enrique, "BIт y la Constitución colombiana de 1991: internacionalización de la economía dentro de un Estado social de derecho", Estudios Socio-Jurídicos, 2011, 13, (1), p. 109.

79 Comunidad indigena sawhoyamaxa c. Paraguay, Corte Interamericana de Derechos Humanos, sentencia, 29 de marzo de 2006. 
México durante la reforma agraria de principios del siglo xx: el mayor monto de la compensación. ${ }^{80}$

Otro párrafo merece la iniciativa de Sudáfrica de reparación histórica redistribuyendo algunos derechos sobre recursos mineros, sin que ello significara el desapoderamiento del inversor extranjero. Si bien el sector minero no puede compararse con el agrícola, el ejemplo sirve para ilustrar las consecuencias de los TPIE. La ley de reparación histórica modificaba los derechos de inversores extranjeros sobre las minas y los sujetaba a que dieran cumplimiento a una serie de requisitos que favorecían a personas víctimas del apartheid. Esto suscitó una demanda arbitral internacional por parte de algunos inversores extranjeros, que veían afectadas sus expectativas legítimas. El caso Foresti c. Sudáfrica nunca llegó a una resolución final, a raíz de un acuerdo entre los inversores y el gobierno sudafricano. ${ }^{81}$

\subsection{El derecho a mantener su plan de negocios frente a una crisis alimentaria}

La seguridad alimentaria del país receptor de la inversión también podría ser materia de controversia. Durante la crisis alimenticia de 2008, varios países prohibieron la exportación de productos agrícolas. ${ }^{82} \mathrm{La}$ existencia de una crisis alimentaria, como muestra este antecedente, puede llevar al Estado receptor de la inversión a tomar medidas que limiten las expectativas de los inversores extranjeros. En principio, una crisis alimentaria justificaría estas medidas, sin perjuicio de los derechos de los inversores. No obstante, el antecedente de los casos contra Argentina por la crisis económica brinda un panorama más incierto. Existen casos decididos contra Argentina a pesar de la emergencia, ${ }^{83}$ y una serie de casos en los que la emergencia justificó las medidas adoptadas por el país, pero solo por un período determinado. ${ }^{84}$ Los casos contra Argentina han dejado

\footnotetext{
80 Ver Lipson, Charles, Standing guard: protecting foreign capital in the nineteenth and twentieth centuries, University of California Press, Berkeley, 1985, p. 78.

81 Piero Foresti c. Sudáfrica, Icsid Case No ARB(AF)/07/01, award, 4 de agosto de 2010, pars. 79.

82 “Los alimentos suben y las presiones aumentan", en Página 12, 2 de mayo de 2008.

83 CMS c. Argentina, Icsid Case No ARB/01/8, award, 12 de mayo de 2005; El Paso c. Argentina, Icsid Case $\mathrm{N}^{\circ} \mathrm{ARB} / 03 / 15$, award, 31 de octubre de 2011; Total c. Argentina, Icsid Case $\mathrm{N}^{\mathrm{O}} \mathrm{ARB} / 04 / 01$, decision on liability, 27 de diciembre de 2010.

84 LGeEE c. Argentina, Icsid Case No ARB/02/1, decision on liability, 3 de octubre de 2006.
} 
dos lecciones. La primera es que, aunque la crisis argentina fue de grandes proporciones, no siempre los tribunales fallaron a favor de este país. La segunda es que resulta importante tener en cuenta en qué medida el país receptor de la inversión pudo haber coadyuvado a generar la crisis. En el caso de una crisis alimentaria generalizada, además, será necesario considerar que el caso involucraría la emergencia tanto del país receptor como del país de origen de la inversión extranjera. Esto, sin dudas, podría jugar un rol en la decisión de una controversia.

\section{Conclusiones}

Este trabajo analizó en qué medida los derechos de propiedad de los inversores extranjeros son diferentes de los nacionales respecto de la tierra y los emprendimientos agrícolas. En ciertas circunstancias, los TPIE y los arbitrajes de inversiones pueden transformar las expectativas de negocio de los inversores extranjeros en parte concreta de sus derechos. Esta definición del contenido de los derechos puede afectar de manera fundamental la relación entre los inversores extranjeros y los Estados. Las medidas que pueden tomar los Estados sin tener que pagar compensación dependen de los derechos sustanciales de los inversores extranjeros. Las lecciones que surgen del análisis realizado son muy importantes para comprender la relación entre los inversores extranjeros en agricultura y los Estados, especialmente desde la posición de los países latinoamericanos. Los Estados deben ser cuidadosos tanto al firmar contratos como al hacer declaraciones a los inversores extranjeros, prestando atención a su ordenamiento jurídico cuando promueven la inversión extranjera en agricultura. En materia agrícola, sobre todas las cosas, los países deberían establecer organismos de regulación profesionales con la capacidad de proveer evidencia científica que permita justificar medidas regulatorias. Esto ayudaría a resguardar cierta capacidad de los Estados para adoptar medidas regulatorias legítimas sin pagar compensación. El principal problema que presentan los TPIE se refiere a los cambios de política a raíz de nuevas preferencias o demandas de las comunidades. Cambios que no requerirían pagar compensación a inversores nacionales no podrían realizarse frente a los inversores extranjeros sin pagar compensaciones o, en su caso, sin pagar mayores compensaciones. Es aquí donde los derechos de los inversores extranjeros pueden hacer una gran diferencia. 


\section{Referencias bibliográficas}

\section{Doctrina}

Alexander, Gregory, The global debate over constitutional property: lessons for American takings jurisprudence, University of Chicago Press, Chicago, 2006.

Barrère, Christian, "Judicial system and property rights", en Enrico Colombatto (Ed.), The Elgar Companion to the economics of property rights, Edward Elgar Pub., Cheltenham, 2006, p. 129.

Bernasconi-Osterwalder, Nathalie \& Vyoma, Jha, Recent developments in international investment disputes: investment treaty cases from September 2010 to October 2011, International Institute for Sustainable Development, 2012.

Bohoslavsky, Juan Pablo, Tratados de protección de las inversiones e implicaciones para la formulación de políticas públicas (especial referencia a los servicios de agua potable y saneamiento), Cepal, Colección Documentos de Proyectos, 2010.

Bonnal, Philippe; Bosc, Pierre Marie; Díaz, Mario \& Losch, Bruno, "Multifuncionalidad de la agricultura y 'nueva ruralidad'. ¿Reestructuración de las políticas públicas a la hora de la globalización?”, ponencia presentada en el Seminario Internacional El Mundo Rural: Transformaciones y Perspectivas a la Luz de la Nueva Ruralidad, Pontificia Universidad Javeriana, Clacso, Redcapa, Bogotá, 15-17 de octubre de 2003.

Cole, Daniel \& Grossman, Peter, "The meaning of property rights: law versus economics?", Land Economics, 2002, 78, (3), p. 317.

Cotula, Lorenzo, "The new enclosures? Polanyi, international investment law and the global land rush", Third World Quarterly, 2013, 34, p. 1605.

Deininger, Klaus \& Byerlee, Derek, Rising global interest in Farmland: can ityield sustainable and equitable benefits?, World Bank, Washington D.C., 2011.

Douglas, Zachary, "The hybrid foundations of investment treaty arbitration", British Yearbook of International Law, 2003, 74, p. 151.

Dunning, John \& Lundan, Sarianna, Multinational enterprises and the global economy, $2^{\mathrm{a}}$ ed., Edward Elgar, Cheltenham, UK, Northampton, MA, 2008.

FAO, Dinámica del mercado de la tierra en América Latina y el Caribe: concentración y extranjerización, Naciones Unidas, Roma, 2012.

Fietta, Stephen, "Expropriation and the 'fair and equitable' standard", Journal of International Arbitration, 2006, 23, (5), p. 379. 
Gaillard, Emmanuel, "Chronique des sentences arbitrales - Centre International pour le Règlement des Différends Relatifs aux Investissements (Cirdi)", Revue trimestrielle Lexis Nexis Juris Classeur, 2008, p. 311.

García Amador, Francisco, International responsibility. Fourth report, Comisión de Derecho Internacional, A/CN.4/119, 1959.

Gayá, Romina \& Michalczewsky, Kathia, El salto exportador del Mercosur en 2003-2008. Más allá del boom de las materias primas, IDB-Intal, 2011, nota técnica 292.

Gold, Andrew, "A property theory of contract", Northwestern University Law Review, 2009, 103, (1), p. 1.

Gómez, Andrei; Perrone, Nicolás \& Prieto Ríos, Enrique, "Foreign investors and peace in Colombia", International Community Law Review, forthcoming, LASA Conference, 2015.

Honoré, Anthony, "Ownership", en Guest, A. G. (Ed.), Oxford essays in jurisprudence: a collaborative work, Oxford University Press, London, New York, 1961, p. 107.

Jennings, R. Y., "State contracts in international law", British Yearbook of International Law, 1961, 37, p. 156.

Kaushal, Asha, "Revisiting history: how the past matters for the present backlash against the foreign investment regime", Harvard International Law Journal, 2009, 50, (2), p. 491.

Lentini, Emilio \& Fierro, Gonzalo, "Políticas tarifarias y regulatorias en el marco de los Objetivos de Desarrollo del Milenio y el derecho humano al agua y al saneamiento", Cepal - Serie Recursos Naturales e Infraestructura No 164, 2014.

Lipson, Charles, Standing guard: protecting foreign capital in the nineteenth and twentieth centuries, University of California Press, Berkeley, 1985.

Llewellyn, Karl, Jurisprudence: realism in theory and practice, Transaction Publishers, New Brunswick, London, 2000.

Mandelker, Daniel, "Investment-backed expectations: is there a taking?", Journal of Urban and Contemporary Law, 1987, 31, (3), p. 3.

Merrill, Thomas \& Smith, Henry, "Optimal standardization in the law of property: the numerus clausus principle", Yale Law Journal, 2000, 110, p. 1.

Michelman, Frank, "Property as a constitutional right", Washington and Lee Law Review, 1981, 38, p. 1097.

North, Douglas, Structure and change in economic history, W. W. Norton \& Company, New York, 1981. 
Ostrom, Elinor \& Schlager, Edella, "The formation of property rights", en Hanna, Susan; Folke, Carl \& Mäler, Karl-Göran (Eds.), Rights to nature: ecological, economic, cultural, and political principles of institutions for the environment, Island Press, Washington D.C., 1996, p. 137.

Paulsson, Jan, "Universal arbitration - what we gain, what we lose", The Alexander Lecture - Chartered Institute of Arbitrators, 29 de noviembre de 2012 (draft: 3 de diciembre de 2012), p. 10, en http:// www.globalarbitrationreview.com/cdn/files/gar/articles/jan_Paulsson_Universal_Arbitration_-_what_we_gain_what_we_lose.pdf

Penner, James, The idea of property in law, Oxford University Press, Oxford, 2000.

Perrone, Nicolás, "La inversión extranjera en agricultura y los altos precios de los productos primarios: un aporte para comprender el actual desafío del Mercosur", Revista Comercio e Integración, 2012, 35 , p. 63.

Perrone, Nicolás, "The international investment regime and foreign investors' rights: another view of a popular story", Manchester Journal of International Economic Law, 2014, 11, (3), p. 397.

Perrone, Nicolás, The international investment regime and foreign investors' rights: another view of a popular story, Ph. D. thesis, London School of Economics and Political Science, 2013.

Prieto Ríos, Enrique, “BIT y la Constitución colombiana de 1991: internacionalización de la economía dentro de un Estado social de derecho", Estudios Socio-Jurídicos, 2011, 13, (1), p. 109.

Rose, Carol, "Mahon reconstructed: why the takings issue is still a mudd1e", Southern California Law Review, 1984, 57, p. 561.

Rose, Carol, “Takings' and the practices of property: property as wealth, property as 'propriety", en Property and persuasion, Westview Press, Colorado, 1994, p. 50.

Rose-Ackerman, Susan, "Against ad hocery: a comment on Michelman", Columbia Law Review, 1988, 88, p. 1697.

Salacuse, Jeswald \& Sullivan, Nicholas, "Do BIT really work?: an evaluation of bilateral investment treaties and their Grand Bargain", Harvard International Law Journal, 2005, 46, (1), p. 67.

Salacuse, Jeswald, "The emerging global regime for investment", Harvard International Law Journal, 2010, 51, (2), p. 427.

Schneiderman, David, Constitutionalizing economic globalization. Investment rules and democracy's promise, Cambridge University Press, New York, 2008. 
Schønberg, Søren, Legitimate expectations in administrative law, Oxford University Press, New York, 2000.

Schreuer, Christoph \& Kriebaum, Ursula, "At what time must legitimate expectations exist?", en Werner, Jacques \& Ali, Arif (Eds.), A liber amicorum: Thomas Wälde, CMP Publishing Ltd, London, 2009, p. 265.

Schulz, Clifford \& Weber, Gregory, "Changing judicial attitudes towards property rights in California water resources: from vested rights to utilitarian reallocations", Pacific Law Journal, 1987, 19, p. 1031.

Segrelles, José Antonio, "Una reflexión sobre la reciente reorganización de los usos agropecuarios en América Latina", Anales de Geografía de la Universidad Complutense, 2007, 27, (1), p. 125.

Shemberg, Andrea, Stabilization clauses and buman rights, International Finance Corporation and the United Nations Special Representative to the Secretary General on Business and Human Rights, 2008.

Sherwin, Emily, "Two-and three- dimensional property rights", Arizona Law Review, 1997, 29, p. 1075.

Sornarajah, M., "The case against a regime on international investment law", en Trakman, Leon \& Ranieri, Nick (Eds.), Regionalism in international investment law, Oxford University Press, New York, 2013, p. 494.

Stiglitz, Joseph, "Regulating multinational corporations: towards principles of cross-border legal frameworks in a globalized world: balancing rights with responsibilities", American University International Law Review, 2008, 23, p. 451.

Stumberg, Robert, Reform of investor protections. Review of the model U.S. bilateral investment treaty, U.S. Department of State \& Office of the U.S. Trade Representative, 29 de julio de 2009.

Unctad, Bilateral investment treaties 1995-2006: trends in investment rulemaking, Naciones Unidas, Nueva York y Ginebra, 2007, p. 8.

Unctad, World investment report 2012: towards a new generation of investment policies, Naciones Unidas, Nueva York y Ginebra, 2012.

Van Harten, Gus, Investment treaty arbitration and public law, Oxford University Press, New York, 2007.

Von Walter, André, “The investor's expectations in international investment arbitration", Transnational Dispute Management, 2009, 6, (1), p. 1.

Waldron, Jeremy, The right to private property, Clarendon Press, Oxford, 1988.

Waldron, Jeremy, The rule of law and the measure of property, Cambridge University Press, Cambridge, 2012.

Weber, Max, Economy and society, editado por Guenther Roth y Claus Wittich, Bedminster Press, New York, 1968, vol. 1. 


\section{Medios de prensa}

"Labriegos y defensores de semillas, indignados por decisiones del ICA", en El Tiempo, 30 de noviembre de 2013, en http:/ /www.eltiempo. com/archivo/documento/CMS-13236396

"Los alimentos suben y las presiones aumentan", en Página 12, 2 de mayo de 2008, en http://www.pagina12.com.ar/diario/elpais/1-103421-2008-05-02.html

\section{Laudos y decisiones internacionales}

Aguas del Tunari c. Bolivia, Icsid Case $\mathrm{N}^{\circ} \mathrm{ARB} / 02 / 3$.

Azurix c. Argentina, Icsid Case No ARB/01/12, award, 14 de julio de 2006.

Bayview Irrigation c. México, Icsid Case $\mathrm{N}^{\mathrm{o}} \mathrm{ARB}(\mathrm{AF}) / 05 / 1$, award, 19 de junio de 2007.

Burlington c. Ecuador, Icsid Case $\mathrm{N}^{\circ} \mathrm{ARB} / 08 / 5$, decision on liability, $14 \mathrm{de}$ diciembre de 2012.

Chemtura c. Canadá, Uncitral-Nafta, award, 2 de agosto de 2010.

CMS c. Argentina, Icsid Case No ARB/01/8, award, 12 de mayo de 2005.

Comunidad indigena sawhoyamaxa c. Paraguay, Corte Interamericana de Derechos Humanos, sentencia, 29 de marzo de 2006.

Continental c. Argentina, Icsid Case No ARB/03/9, award, 5 de septiembre de 2008.

Duke c. Ecuador, Icsid Case No ARB/04/19, award, 18 de agosto de 2008. EDF c. Rumania, Icsid Case $\mathrm{N}^{\circ}$ ARB/05/13, award, 8 de octubre de 2009. ElPaso c. Argentina, Icsid Case No ARB/03/15, award, 31 de octubre de 2011. Feldman c. México, Icsid Case $\mathrm{N}^{\mathrm{o}} \mathrm{ARB}(\mathrm{AF}) / 99 / 1$, award, 16 de diciembre de 2002.

Frontier Petroleum c. República Checa, Uncitral, award, 12 de noviembre de 2010.

Genin c. Estonia, Icsid Case No ARB/99/2, award, 25 de junio de 2001.

Glamis c. USA, Uncitral-Nafta, award, 8 de junio de 2009.

International Thunderbird c. México, Nafta-Uncitral, opinión de Thomas Wälde, $1^{\circ}$ de diciembre de 2005.

Ioannis Kardassopoulos c. Georgia, Icsid Case No ARB/05/18, award, 3 de marzo de 2010.

LG\&E c. Argentina, Icsid Case $\mathrm{N}^{\circ}$ ARB/02/1, decision on liability, 3 de octubre de 2006.

Mafferinic. Spain, Icsid Case No ARB/97/7, award, 13 de noviembre de 2000. 
Merrill c. Canadá, Uncitral, Icsid Administered Case - Nafta, award, 31 de marzo de 2010.

Methanex c. USA, Uncitral-Nafta, final award of the Tribunal on Jurisdiction and Merits, 3 de agosto de 2005.

National Grid Plc. c. Argentina, Uncitral, award, 3 de noviembre de 2008. OKO v. Estonia, Icsid Case No ARB/04/6, award, 19 de noviembre de 2007. Piero Foresti c. Sudáfrica, Icsid Case $\mathrm{N}^{\circ} \mathrm{ARB}(\mathrm{AF}) / 07 / 01$, award, 4 de agosto de 2010.

Pope \& Talbot c. Canadá, Uncitral-Nafta, award in respect of damages, 31 de mayo de 2002.

Pope \& Talbot c. Canadá, Uncitral-Nafta, interim award, 26 de junio de 2000. Saluka c. República Checa, Uncitral, partial award, 17 de marzo de 2006.

SD Myers c. Canadá, Uncitral-Nafta, partial award, 13 de noviembre de 2000. Sergei Paushoke. Mongolia, Uncitral, award on jurisdiction and liability, 28 de abril de 2011.

Spyridon Roussalis c. Romania, Icsid Case $\mathrm{N}^{\circ} \mathrm{ARB} / 06 / 1$, award, 7 de diciembre de 2011.

Suez. c. Argentina, Icsid Case No ARB/03/17, opinión de Pedro Nikken, 30 de julio de 2010.

Tecmed c. México, Icsid Case No ARB(AF)/00/2, award, 29 de mayo de 2003.

Total c. Argentina, Icsid Case No ARB/04/01, decision on liability, 27 de diciembre de 2010. 